\title{
Olmesartan medoxomil for the treatment of hypertension in children and adolescents
}

\author{
This article was published in the following Dove Press journal: \\ Vascular Health and Risk Management \\ 30 March 20II \\ Number of times this article has been viewed
}

\author{
Giuliano Tocci' \\ Massimo Volpe ${ }^{1,2}$ \\ 'Chair and Division of Cardiology, \\ Department of Clinical and Molecular \\ Medicine, Faculty of Medicine, \\ University of Rome "Sapienza", \\ Sant'Andrea Hospital, Rome; \\ IRCCS Neuromed, Pozzilli, Italy
}

\begin{abstract}
Prevalence of hypertension in children and adolescents has progressively and continuously increased over recent decades. Thus, early and effective control of high blood pressure may be considered an effective therapeutic approach, in order to reduce the burden of hypertension-related cardiovascular disease in future. In the past, due to the absence of prospective, long-term, randomized, controlled clinical trials performed in young hypertensive patients, lifestyle changes have been long seen as the only strategy to reduce high blood pressure levels. More recently, clinical data on the efficacy and safety of five major classes of antihypertensive drugs (including angiotensin converting enzyme inhibitors, angiotensin receptor blockers [ARBs], beta-blockers, calcium-antagonists, and diuretics) have become available. In particular, these trials demonstrated dose-dependent blood pressure reductions and a good tolerability profile of several ARBs in hypertensive children and adolescents. An overview is provided of the clinical benefits of early detection and prompt intervention of high blood pressure levels, with a closer analysis of recent clinical trials, performed with olmesartan medoxomil in young subjects with hypertension.
\end{abstract}

Keywords: hypertension, high blood pressure, children, adolescents, antihypertensive treatment, olmesartan medoxomil

\section{Introduction}

Effective treatment of high blood pressure (BP) represents a key strategy in reducing the burden of cardiovascular $(\mathrm{CV})$ and renal diseases. ${ }^{1-3}$ Consistent findings have demonstrated significant reductions in $\mathrm{CV}$ and renal morbidity and mortality through the systematic use of different BP-lowering strategies in adult populations. ${ }^{4-7}$ In spite of these well-established concepts, hypertension remains poorly controlled in both Western countries $^{8,9}$ and in developing countries. ${ }^{10-12}$ In view of the progressively increasing prevalence of hypertension in children and adolescents, ${ }^{13,14}$ early and effective control of BP may be considered an effective therapeutic approach for reducing the burden of hypertension-related CV disease.

Observational surveys have demonstrated that high BP levels are frequently associated with other concomitant CV risk factors, including obesity, dyslipidemia, metabolic syndrome, and diabetes in young individuals. ${ }^{15-18}$ This clustering of multiple, concomitant $\mathrm{CV}$ risk factors may exert different effects according to target populations: while in adulthood it raises the susceptibility for developing major CV and renal events, including acute myocardial infarction, stroke, and heart and renal failure, ${ }^{19,20}$ in childhood it may substantially promote an acceleration of the risk of developing established CV disease in adult age..$^{21,22}$ In other words, young subjects with high BP levels, 
hypercholesterolemia, metabolic syndrome, or impaired glucose regulation have greater susceptibility to develop these clinical conditions with aging, thus contributing to an increased burden of $\mathrm{CV}$ disease in the general population. These features make hypertension a potential target to reduce $\mathrm{CV}$ morbidity in young subjects and to improve prevention of CV morbidity and mortality in adult individuals. ${ }^{23}$

This latter point has prompted the search for agents or strategies that exert an early and effective BP control and that, at the same time, are able to provide benefits in terms of organ protection, beyond BP-lowering effects, with a low incidence of side effects and good tolerability profile, which represents important properties in young individuals. ${ }^{24,25}$

In view of the progressively large diffusion of hypertension and BP-related clinical diseases in children and adolescents, and of the objective difficulties of applying lifestyle changes in this specific age group, the use of antihypertensive drugs, especially in those patients not controlled with lifestyle changes, may enable improved BP control and reduce the burden of $\mathrm{CV}$ disease in young individuals.

This paper provides an overview of the main findings of a recent clinical trial, performed with olmesartan medoxomil in young individuals, and discusses the clinical benefits derived from early detection and prompt intervention of high BP levels in children and adolescents. According to the aim of our study, a comprehensive search strategy was performed through online medical databases (Medline and Embase) by using the following search terms: "hypertension", "high blood pressure", "children", "adolescents", "olmesartan medoxomil". Among the large number of articles made available from this research, only those which have been published in English, in peer-reviewed journals, and with full access to entire contents of the paper have been selected and discussed in this paper.

\section{Hypertension management in children and adolescents}

Diagnostic criteria for high BP levels in children and adolescents are based on the concept that BP progressively increases according to age, height and body size. ${ }^{26,27}$ Since a single BP threshold to define hypertension is not applicable in young individuals, BP targets are commonly defined in relation to the distribution of BP in the normal young population. Thus, normal BP in children and adolescents is defined as systolic and diastolic BP levels less than the 90th percentile for age, sex, and height, whereas hypertension is defined as systolic and diastolic BP levels persistently on the 95 th percentile or more, measured on at least three separate visits. ${ }^{26,27}$
As for hypertension definition, BP targets to be achieved with treatment vary according to the characteristics of general population. ${ }^{26,27}$ In the past, lifestyle changes have been highly recommended to reduce high BP levels in young hypertensive patients. More recently, international guidelines recommend that, when required and usually after a 3- to 6-month period of lifestyle changes, antihypertensive treatment should be started with a single drug administered at a low dose, in order to avoid a rapid fall in $\mathrm{BP}^{26-28}$

When antihypertensive drug therapy is needed, the first choice of antihypertensive agents can be made among all five classes of antihypertensive drugs. ${ }^{26,27}$ This is mostly based on the fact that only few placebo-controlled studies are available, but almost no head-to-head studies directly comparing the efficacy and safety of different antihypertensive drugs in children or adolescents have been conducted. Since the rennin-angiotensin system (RAS) is intimately involved in different pathophysiological mechanisms leading to development and progression of hypertension, RAS blocking agents, such as angiotensin-converting enzyme (ACE) inhibitors and angiotensin II receptor blockers (ARBs), are now viewed as suitable and useful therapeutic tools to antagonize the deleterious consequences of RAS abnormal activity in hypertension-related disease conditions, including metabolic syndrome, ${ }^{29}$ diabetes, ${ }^{30}$ and organ damage, ${ }^{31}$ in the presence of an effective BP-lowering efficacy and good tolerability profile. In this regard, a recent analysis of 27 clinical trials performed in young individuals with hypertension reported comparable BP reductions with ACE inhibitors, ARBs, and calcium-channel blockers. ${ }^{32}$ In particular, clinical data on the efficacy, safety, and tolerability of ARB-based therapy in hypertensive children have become recently available. These trials demonstrated dose-dependent BP reductions and a good tolerability profile of several ARB compounds, such as losartan 0.75 to $1.44 \mathrm{mg} / \mathrm{kg}$, candesartan 0.16 to $0.47 \mathrm{mg} / \mathrm{kg}$, valsartan $2 \mathrm{mg} / \mathrm{kg}$ per day, and irbesartan 75 to $150 \mathrm{mg}$ daily. ${ }^{26}$ More recently, interesting clinical data demonstrating the efficacy and tolerability of olmesartan medoxomil have become available. ${ }^{33}$

\section{Pharmacodynamics, pharmacokinetics and clinical efficacy of olmesartan Pharmacodynamics}

Olmesartan medoxomil is an orally administered prodrug of olmesartan, a non-peptide ARB that has high selectivity for the AT1 receptor, to which it is highly bound, having a limited affinity to the AT2 receptor. ${ }^{34}$ Since activation 
of the AT1 receptor by angiotensin II induces arteriolar vasoconstriction, sympathetic nervous system activation, salt and water retention, and aldosterone secretion, ${ }^{35}$ olmesartan is presumed to reduce high BP levels mostly by blocking the vasoconstrictor and aldosterone-secreting effects of angiotensin II. ${ }^{36,37}$ Consistent with this mechanism of action, animal and human studies demonstrated that the effects of olmesartan medoxomil on BP parallel the inhibitory effects on RAS activation. ${ }^{36}$

In animal models, olmesartan also reduced production of markers of early CV inflammation, ${ }^{38}$ myocardial remodeling, ${ }^{39}$ and cardiac fibrosis. ${ }^{40}$ In addition, it reduced in a dose-dependent fashion urinary protein excretion and the area of plaque lesions and intimal wall thickening in cross sections of the aorta. ${ }^{41}$ In patients with hypertension, olmesartan produces gradual and sustained dose-dependent reductions in both systolic and diastolic BP levels, without first-dose hypotension, tachyphylaxis during extended treatment or rapid rebound hypertension, when treatment is discontinued. ${ }^{42,43}$

\section{Pharmacokinetics}

Olmesartan medoxomil is a prodrug that is rapidly hydrolyzed into olmesartan in the gastrointestinal tract. ${ }^{36,44}$ It is rapidly absorbed from the gastrointestinal tract, with a maximum plasma concentration $\left(\mathrm{C}_{\max }\right)$ of 0.22 to $2.1 \mathrm{mg} / \mathrm{L}$, a time to $\mathrm{C}_{\text {max }}$ of 1.4 ti 2.8 hours, and a mean area under the concentrationtime curve (AUC) of 1.6 ti $19.9 \mathrm{mgh} / \mathrm{L}$, following administration of olmesartan medoxomil 10 to $160 \mathrm{mg}{ }^{45}$

Olmesartan is the only metabolite of olmesartan medoxomil. It is excreted mainly in the feces (about 60\%) and the urine; in children, approximately $3 \%$ to $15 \%$ was recovered in the urine. ${ }^{46}$ The mean terminal elimination half-life was 12 to 18 hours for $20 \mathrm{mg}$ olmesartan, ${ }^{45}$ which compares favorably with the half-lives of some other ARBs: irbesartan (11 to 15 hours), losartan (2 hours) and its active metabolite (4 to 5 hours), and valsartan (6 hours). ${ }^{47}$ Finally, olmesartan is not metabolized by cytochrome P-450 enzymes and, therefore, it is unlikely to interact with other drugs that inhibit, induce, or are metabolized by cytochrome P-450 enzymes. ${ }^{48,49}$

The pharmacokinetics of oral olmesartan medoxomil have been investigated in relatively small, open-label studies performed in pediatric patients with hypertension..$^{50}$ More recently, the antihypertensive efficacy, safety, and tolerability of oral olmesartan medoxomil in the treatment of hypertension in children and adolescents (aged 6 to 16 years) was investigated in a randomized, double-blind, multinational, phase II/III trial. ${ }^{33}$ The main findings of this study confirmed the potential benefits derived from the use of this drug in the young population, in terms of BP-lowering efficacy and a good tolerability profile..$^{50}$

\section{Clinical efficacy, safety, and tolerability in children and adolescents}

The Assessment of Efficacy and Safety of Olmesartan in Pediatric Hypertension (AESOP) study ${ }^{33}$ was a randomized, multicenter, double-blind, parallel-group, dose-ranging prospective clinical trial performed in young individuals of any race, aged 6 to 16 years, and presenting with primary or secondary hypertension. The primary endpoint was the efficacy and safety profile of olmesartan medoxomil in children and adolescents with hypertension, defined as systolic BP above the 95th percentile for age, gender, and height. ${ }^{33}$ This trial was specifically requested by the United States Food and Drug Administration, for approving drug prescriptions in young individuals.

The trial was conducted in two distinct periods, with two cohorts in each period. Enrolled individuals were stratified according to ethnicity (cohort A: 62\% Caucasian, 18\% Black, $10 \%$ Asian, and 14\% other races; cohort B, 100\% Black). In period 1, patients were randomized to receive either lowdose (2.5 to $5 \mathrm{mg}$ ) or high-dose (20 to $40 \mathrm{mg}$ ) olmesartan daily for 3 weeks. In period 2, patients maintained their olmesartan dose (active treatment) or initiated placebo washout for an additional 2 weeks.

Among 422 individuals who were initially screened, 302 were randomly assigned to the two cohorts (cohort A: $\mathrm{n}=190$ and cohort $B: n=112$ ). In particular, 95 and 56 patients were randomly assigned to each of the olmesartan dose groups in cohort A and B, respectively.

During the first period, the primary efficacy analyses were based on the changes from baseline in trough seated systolic and diastolic BP levels at the end of period 1 in cohorts. Reductions in both systolic and diastolic BP levels were consistently greater in the high-dose group than in the low-dose group, and they were smaller in cohort B than in cohort A. These differences were statistically significant, even after adjustment for baseline body weight.

Among patients included in period 1 analysis, 13 individuals did not enter period 2, resulting in a total of 182 patients in cohort $\mathrm{A}$ and 107 patients in cohort B, respectively. BP changes were analyzed from period 2 baseline (end of period 1) through the end of period 2 (last observation carried forward). Among patients included in cohort A, the mean increase in seated systolic BP was $0.43 \mathrm{mmHg}$ for subjects on active treatment and $4.9 \mathrm{mmHg}$ for subjects receiving 
placebo (BP difference between active treatment and placebo of $-3.6 \mathrm{mmHg} ; P=0.0093)$. Among individuals included in cohort $\mathrm{B}$, the mean seated systolic BP increase $(1.4 \mathrm{mmHg})$ for subjects on active treatment was lower than that reported in subjects on placebo $(3.8 \mathrm{mmHg} ; P=\mathrm{NS})$.

The percentage of patients experiencing a treatmentemergent adverse event within each cohort was low and similar for the low- and high-dose active treatment groups. The majority of adverse effects were mild or moderate in intensity and were considered unrelated to active therapy.

\section{Conclusions and perspectives}

Hypertension in children and adolescents is a growing epidemiological problem. The progressive rise of average BP levels among young individuals definitely parallels the dramatic increase in overweight, obesity, metabolic syndrome, impaired glucose regulation, and diabetes that we are witnessing. Therefore, a higher commitment to the measurement of BP, diagnosis of hypertension, and therapeutic interventions (virtuous lifestyle changes and drug therapy, when required) should be undertaken and promoted in young subjects.

Population strategies to prevent development of hypertension at a young age, with particular regard to the quality of diet, routine exercise or regular physical activity, and banning of cigarette smoking, need to be actively promoted. Similar measures should be also applied at a clinical level in the individual patient, especially when concomitant predisposing risk factors are present.

Drug therapy should be undertaken prudently, when required. Drugs that may provide a satisfactory BP control in monotherapy and that have few side effects and do not interfere with the quality of life in children and adolescents are highly recommended. ${ }^{26,27}$ In this regard, ARBs have been sufficiently explored in young hypertensive patients, and seem to have a substantially good record. Among these drugs, olmesartan medoxomil has been recently tested with a rigorous clinical trial program in a population of children and adolescents aging from 6 to 16 years and belonging to Caucasian or Black ethnic groups. ${ }^{33}$ The results of this study have been satisfactory in terms of BP reduction and tolerability profile. ${ }^{33}$ Together with the organ protection and the neutral metabolic effects provided by ARBs through the selective antagonism of RAS, olmesartan appears to hold more than a good promise for an effective and safe treatment of children and adolescents with hypertension.

\section{Disclosure}

MV has received research grants from Novartis, has served in international advisory boards of sanofi-aventis, Bayer, Novartis, Boehringer Ingelheim, and Daichii Sankyo, and has lectured in symposia supported by several drug companies producing ARBs; GT has no conflict of interest to disclose.

\section{References}

1. Mancia G, De Backer G, Dominiczak A, et al. 2007 Guidelines for the Management of Arterial Hypertension: The Task Force for the Management of Arterial Hypertension of the European Society of Hypertension (ESH) and of the European Society of Cardiology (ESC). J Hypertens. 2007;25(6):1105-1187.

2. Chobanian AV, Bakris GL, Black HR, et al. The Seventh Report of the Joint National Committee on Prevention, Detection, Evaluation, and Treatment of High Blood Pressure: the JNC 7 report. JAMA. 2003; 289(19):2560-2572.

3. Williams B, Poulter NR, Brown MJ, et al. Guidelines for management of hypertension: report of the fourth working party of the British Hypertension Society, 2004-BHS IV. J Hum Hypertens. 2004;18(3):139-185.

4. Neal B, MacMahon S, Chapman N. Effects of ACE inhibitors, calcium antagonists, and other blood-pressure-lowering drugs: results of prospectively designed overviews of randomised trials. Blood Pressure Lowering Treatment Trialists' Collaboration. Lancet. 2000; 356(9246):1955-1964.

5. Turnbull F. Effects of different blood-pressure-lowering regimens on major cardiovascular events: results of prospectively-designed overviews of randomised trials. Lancet. 2003;362(9395):1527-1535.

6. Turnbull F, Neal B, Algert C, et al. Effects of different blood pressurelowering regimens on major cardiovascular events in individuals with and without diabetes mellitus: results of prospectively designed overviews of randomized trials. Arch Intern Med. 2005;165(12):1410-1419.

7. Turnbull F, Neal B, Ninomiya T, et al. Effects of different regimens to lower blood pressure on major cardiovascular events in older and younger adults: meta-analysis of randomised trials. BMJ. 2008; 336(7653):1121-1123.

8. Wolf-Maier K, Cooper RS, Banegas JR, et al. Hypertension prevalence and blood pressure levels in 6 European countries, Canada, and the United States. JAMA. 2003;289(18):2363-2369.

9. Wolf-Maier K, Cooper RS, Kramer H, et al. Hypertension treatment and control in five European countries, Canada, and the United States. Hypertension. 2004;43(1):10-17.

10. Nakamura K, Barzi F, Lam TH, et al. Cigarette smoking, systolic blood pressure, and cardiovascular diseases in the Asia-Pacific region. Stroke. 2008;39(6):1694-1702.

11. Martiniuk AL, Lee CM, Lawes CM, et al. Hypertension: its prevalence and population-attributable fraction for mortality from cardiovascular disease in the Asia-Pacific region. J Hypertens. 2007;25(1):73-79.

12. Barzi F, Patel A, Woodward M, et al. A comparison of lipid variables as predictors of cardiovascular disease in the Asia Pacific region. Ann Epidemiol. 2005;15(5):405-413.

13. Kelishadi R, Ardalan G, Gheiratmand R, et al. Blood pressure and its influencing factors in a national representative sample of Iranian children and adolescents: the CASPIAN Study. Eur J Cardiovasc Prev Rehabil. Dec 2006;13(6):956-963.

14. Genovesi S, Antolini L, Gallieni M, et al. High prevalence of hypertension in normal and underweight Indian children. J Hypertens. 2011; 29(2):217-221.

15. Rumboldt M, Pavlicevic I, Kuzmanic M, Rumboldt Z. Prevalence of hypertension in school children. J Hypertens. 2008;26(3):610-611; author reply 611-612. 
16. Sorof JM, Lai D, Turner J, Poffenbarger T, Portman RJ. Overweight, ethnicity, and the prevalence of hypertension in school-aged children. Pediatrics. 2004;113(3 Pt 1):475-482.

17. Sorof JM. Prevalence and consequence of systolic hypertension in children. Am J Hypertens. 2002;15(2 Pt 2):57S-60S.

18. Kelishadi R. Childhood overweight, obesity, and the metabolic syndrome in developing countries. Epidemiol Rev. 2007;29:62-76.

19. McQueen MJ, Hawken S, Wang X, et al. Lipids, lipoproteins, and apolipoproteins as risk markers of myocardial infarction in 52 countries (the INTERHEART study): a case-control study. Lancet. 2008;372(9634): 224-233.

20. Yusuf S, Hawken S, Ounpuu S, et al. Effect of potentially modifiable risk factors associated with myocardial infarction in 52 countries (the INTERHEART study): case-control study. Lancet. 2004;364(9438) 937-952.

21. Bao W, Threefoot SA, Srinivasan SR, Berenson GS. Essential hypertension predicted by tracking of elevated blood pressure from childhood to adulthood: the Bogalusa Heart Study. Am J Hypertens. 1995;8(7): 657-665.

22. Chen W, Srinivasan SR, Ruan L, Mei H, Berenson GS. Adult hypertension is associated with blood pressure variability in childhood in blacks and whites: the bogalusa heart study. Am J Hypertens. 2011;24(1): 77-82.

23. Berenson GS, Wattigney WA, Bao W, Nicklas TA, Jiang X, Rush JA. Epidemiology of early primary hypertension and implications for prevention: the Bogalusa Heart Study. J Hum Hypertens. 1994;8(5): 303-311.

24. Volpe M, Erhardt LR, Williams B. Managing cardiovascular risk: the need for change. J Hum Hypertens. 2008;22(2):154-157.

25. Williams B. Recent hypertension trials: implications and controversies. J Am Coll Cardiol. 2005;45(6):813-827.

26. Lurbe E, Cifkova R, Cruickshank JK, et al. Management of high blood pressure in children and adolescents: recommendations of the European Society of Hypertension. J Hypertens. 2009;27(9):1719-1742.

27. The fourth report on the diagnosis, evaluation, and treatment of high blood pressure in children and adolescents. Pediatrics. 2004; 114(2 Suppl 4th Report):555-576.

28. Update on the 1987 Task Force Report on High Blood Pressure in Children and Adolescents: a working group report from the National High Blood Pressure Education Program. National High Blood Pressure Education Program Working Group on Hypertension Control in Children and Adolescents. Pediatrics. 1996;98(4 Pt 1):649-658.

29. Yamada S. Pleiotropic effects of ARB in metabolic syndrome. Curr Vasc Pharmacol. 2011;9(2):158-161.

30. Saitoh S, Takeishi Y. Pleiotropic effects of ARB in diabetes mellitus. Curr Vasc Pharmacol. 2011;9(2):136-144.

31. Papadopoulos DP, Papademetriou V, Makris TK. On target to dual block RAS? Angiology. 2009;60(6):739-749.

32. Simonetti GD, Rizzi M, Donadini R, Bianchetti MG. Effects of antihypertensive drugs on blood pressure and proteinuria in childhood. J Hypertens. 2007;25(12):2370-2376.

33. Hazan L, Hernandez Rodriguez OA, Bhorat AE, Miyazaki K, Tao B, Heyrman R. A double-blind, dose-response study of the efficacy and safety of olmesartan medoxomil in children and adolescents with hypertension. Hypertension. 2010;55(6):1323-1330.
34. Warner GT, Jarvis B. Olmesartan medoxomil. Drugs. 2002;62(9): 1345-1353; discussion 1354-1346.

35. Volpe M, Musumeci B, De Paolis P, Savoia C, Morganti A. Angiotensin II AT2 receptor subtype: an uprising frontier in cardiovascular disease? $J$ Hypertens. 2003;21(8):1429-1443.

36. Brunner HR. Olmesartan medoxomil: current status of its use in monotherapy. Vasc Health Risk Manag. 2006;2(4):327-340.

37. Puchler K, Laeis P, Stumpe KO. Blood pressure response, but not adverse event incidence, correlates with dose of angiotensin II antagonist. $J$ Hypertens Suppl. 2001;19(1):S41-S48.

38. Usui M, Egashira K, Tomita H, et al. Important role of local angiotensin II activity mediated via type 1 receptor in the pathogenesis of cardiovascular inflammatory changes induced by chronic blockade of nitric oxide synthesis in rats. Circulation. 2000;101(3):305-310.

39. Takemoto M, Egashira K, Tomita H, et al. Chronic angiotensinconverting enzyme inhibition and angiotensin II type 1 receptor blockade: effects on cardiovascular remodeling in rats induced by the long-term blockade of nitric oxide synthesis. Hypertension. 1997;30(6): 1621-1627.

40. Tomita H, Egashira K, Ohara Y, et al. Early induction of transforming growth factor-beta via angiotensin II type 1 receptors contributes to cardiac fibrosis induced by long-term blockade of nitric oxide synthesis in rats. Hypertension. 1998;32(2):273-279.

41. Koike H, Sada T, Mizuno M. In vitro and in vivo pharmacology of olmesartan medoxomil, an angiotensin II type AT1 receptor antagonist. J Hypertens Suppl. 2001;19(1):S3-S14.

42. Scott LJ, McCormack PL. Olmesartan medoxomil: a review of its use in the management of hypertension. Drugs. 2008;68(9):1239-1272.

43. Unger T, McInnes GT, Neutel JM, Bohm M. The role of olmesartan medoxomil in the management of hypertension. Drugs. 2004;64(24): 2731-2739.

44. Brousil JA, Burke JM. Olmesartan medoxomil: an angiotensin IIreceptor blocker. Clin Ther. 2003;25(4):1041-1055.

45. Schwocho LR, Masonson HN. Pharmacokinetics of CS-866, a new angiotensin II receptor blocker, in healthy subjects. J Clin Pharmacol. 2001;41(5):515-527.

46. Von Bergmann K, Laeis P, Puchler K, Sudhop T, Schwocho LR, Gonzalez L. Olmesartan medoxomil: influence of age, renal and hepatic function on the pharmacokinetics of olmesartan medoxomil. J Hypertens Suppl. 2001;19(1):S33-S40.

47. Stumpe KO. Olmesartan compared with other angiotensin II receptor antagonists: head-to-head trials. Clin Ther. 2004;26 Suppl A: A33-A37.

48. Wehling M. Can the pharmacokinetic characteristics of olmesartan medoxomil contribute to the improvement of blood pressure control? Clin Ther. 2004;26 Suppl A:A21-A27.

49. Laeis P, Puchler K, Kirch W. The pharmacokinetic and metabolic profile of olmesartan medoxomil limits the risk of clinically relevant drug interaction. J Hypertens Suppl. 2001;19(1):S21-S32.

50. Muir VJ, Keating GM. Olmesartan medoxomil: in children and adolescents with hypertension. Drugs. 2010;70(18):2439-2447.
Vascular Health and Risk Management

\section{Publish your work in this journal}

Vascular Health and Risk Management is an international, peerreviewed journal of therapeutics and risk management, focusing on concise rapid reporting of clinical studies on the processes involved in the maintenance of vascular health; the monitoring, prevention and treatment of vascular disease and its sequelae; and the involvement of

\section{Dovepress}

metabolic disorders, particularly diabetes. This journal is indexed on PubMed Central and MedLine. The manuscript management system is completely online and includes a very quick and fair peer-review system, which is all easy to use. Visit http://www.dovepress.com/ testimonials.php to read real quotes from published authors. 